\title{
The neural pathway midline crossing theory: a historical analysis of Santiago Rámon y Cajal's contribution on cerebral localization and on contralateral forebrain organization
}

\author{
Carla Mora, MD, Carlos Velásquez, MD, and Juan Martino, MD, PhD \\ Department of Neurological Surgery and Spine Unit, Hospital Universitario Marqués de Valdecilla and Fundación Instituto de \\ Investigación Valdecilla, Santander, Spain
}

\begin{abstract}
Throughout history, many scientists have wondered about the reason for neural pathway decussation in the CNS resulting in contralateral forebrain organization. Hitherto, one of the most accepted theories is the one described by the renowned Spanish physician, Santiago Rámon y Cajal at the end of the 19th century. This Nobel Prize winner, among his many contributions to science, gave us the answer to this question: the key lies in the optic chiasm. Based on the fact that the ocular lenses invert the image formed in the retina, Cajal explained how the decussation of the fibers in the optic chiasm is necessary to obtain a continuous image of the outside in the brain. The crossing of the tactile and motor pathways occurred posteriorly as a compensatory mechanism to allow the cortical integration of the sensory, motor, and visual functions. This theory had a great influence on the scientific community of his time, and maintains its importance today, in which none of the theories formulated to date has managed to entirely refute Cajal's. In addition, the decussation of neural pathways plays a significant role in different diseases, especially in the recovery process after a hemispheric lesion and in several congenital pathologies. The advantages of cerebral lateralization have also recently been published, although the evolutionary connection between fiber decussation and cortical function lateralization remains a mystery to be solved. A better understanding of the molecular and genetic substrates of the midline crossing processes might result in significant clinical advances in brain plasticity and repair.
\end{abstract}

https://thejns.org/doi/abs/10.3171/2019.6.FOCUS19341

KEYWORDS Santiago Rámon y Cajal; decussation; midline crossing; optic chiasm

$\mathrm{T}$ HE midline crossing of neural pathways in the CNS, resulting in contralateral forebrain organization, is a widely accepted fact and one of the centerpieces of modern neuroscience theories on brain localization. Neural fiber midline crossing occurs at certain specialized points called commissures, when there is a connection of homologous parts of the brain (e.g., corpus callosum), or decussations, when there is a connection between nonhomologous parts (e.g., optic chiasm, pyramidal tract). ${ }^{2}$

Despite the teleological inquiries on these phenomena, conducted by several neuroscientists over the centuries, the primary and evolutionary bases behind the neural pathway crossing remain unclear. More than a century ago, Santiago Ramón y Cajal (1852-1934), the renowned Spanish neuroanatomist, with his detailed description of the histological structure of the optic chiasm, proposed the theory of neural pathway midline crossing, ${ }^{30}$ one of the most intelligible explanations on this subject to date.
In this historical review, we revisit the question on nerve pathway midline crossing in light of Cajal's theory as one of the most relevant contributions to the current understanding of brain function and localization. We aim to summarize the history of its description and to analyze its repercussion in the scientific community of the time. Moreover, an analysis on the limitations of Cajal's theory is performed by contraposition of alternative and novel theories on the subject. Finally, we discuss the clinical implications of fiber midline crossing and its implications on brain dominance.

\section{History of the Theories on Nerve Fiber Midline Crossing}

The idea of the contralateral organization of the forebrain, and hence of the crossed nature of motor fibers, was first recognized in the Golden Age of Greece by Hip- 
pocrates (460-380 вс). Furthermore, in the Corpus Hippocraticum we can find a detailed description on how "convulsions seize the other side of the body." ",18 Nevertheless, Aretaeus of Cappadocia (1st or 2nd century AD), a contemporary of Galen, went beyond Hippocrates' findings. In his treatise on apoplexy, the Morborum acutorum, de curatione apoplexiae, he depicts the first notion of the motor tract decussation by distinguishing ipsilateral and contralateral paralyses elicited by spinal cord or brain injuries, respectively. ${ }^{29}$ These observations were reproduced later by other scientists, such as by Johann Jakob Wepfer in 1724 (1620-1695) in his Historiae apoplecticorum. ${ }^{28}$

But it was not until the 18th-19th centuries that the main sensorimotor decussations were discovered. The pyramidal decussation in the medulla was first described by Domenico Mistichelli (1675-1715) and François Pourfour du Petit (1664-1741) in 1709 and 1710, respectively, and later dissected from the pyramids to the cerebral cortex by Franz Josef Gall (1758-1828) and Johann Gaspar Spürzheim (1776-1832). ${ }^{42}$ The medial lemniscus was discovered by Albrecht von Haller (1708-1777) in 1765 and Johann Christian Reil (1759-1813) in 1809.32 And finally, the decussation of spinothalamic tracts in the spinal cord was demonstrated by Charles-Édouard Brown-Séquard (1817-1894) in 1846.,26

Despite the significant progress in the knowledge of the structure of the CNS and its crossed-wired organization, no hypothesis on the teleology of these phenomena was proposed. Nevertheless, the seminal work of this group of neuroanatomists over 2 centuries laid the neuroanatomical foundations for Rámon y Cajal to develop his theory on the nerve-tract midline crossing in relation to the anatomy of the optic chiasm. ${ }^{30}$

In 1898, Rámon y Cajal published the most exhaustive research on the decussation of fibers at that time. This study was also motivated by the revolutionary work published by the ophthalmologist Julius von Michel (1843-1911) at the end of the 19th century. ${ }^{25}$ In this work, contrary to everything known from the time of Newton, it was mentioned that the optic chiasm of man and vertebrates is formed only of crossed pathways. Until then, it was believed that there was a partial crossing of the fibers at the level of the optic chiasm. Michel's findings caused great surprise at the time, but it won the approval of some renowned scientists such as Albert von Kölliker $(1817-1905) .^{22}$ Cajal, in order to verify this theory, devoted himself to exhaustive observations of the optic nerves of fish, amphibians, reptiles, birds, mice, and higher mammals. He pointed out the error in which Michel and Kölliker had incurred by their use of the Weigert method for their studies, in which nerve fibers are difficult to follow. In his experiments, Cajal used methylene blue of the Ehrlich and Marchi method instead and as a result he was able to confirm the classic theory. ${ }^{24,31}$

Moreover, when studying the optic chiasm, Cajal also questioned himself on the unsolved problem regarding the evolutionary explanation of the fiber crossing in the optic pathway (Fig. 1): “...wouldn’t be simpler for each retine to send the optic input directly to its ipsilateral hemisphere?" ${ }^{31}$ Consequently, considering that the ocular lenses invert the image that is formed in the retina with

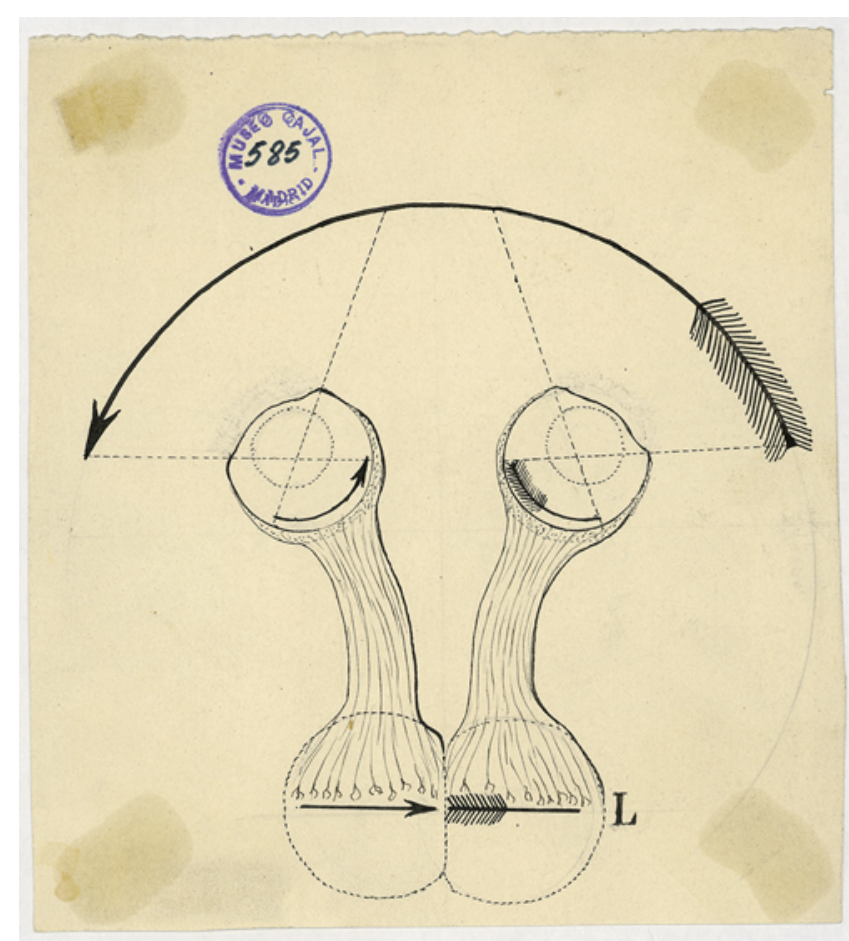

FIG. 1. Ramón y Cajal's schematic drawing showing an optic pathway without a nerve fiber decussation, resulting in an inconsistent cortical representation of the object. Reproduced from Ramón y Cajal S: Estructura del kiasma óptico y teoría general de los entrecruzamientos de las vías nerviosas. Rev Trim Micrografica 3:15-66, 1898. Public domain. Courtesy of the Cajal Institute, "Cajal Legacy," Spanish National Research Council (CSIC), Madrid, Spain.

respect to the original, Cajal suggested that the midline crossing of the visual pathway in the chiasm was necessary to obtain a continuous image of the exterior in the brain. ${ }^{37} \mathrm{He}$ hypothesized how the crossing of these fibers in the chiasm can be partial or total depending on the existence of stereoscopic vision. In animals without stereoscopic vision, the lateral eyes allow the panoramic view and the exploration of predators, and the complete crossing of the fibers in the optic chiasm is necessary to restore a congruent image. ${ }^{30}$

In contrast, in animals with forward-facing eyes, the visual fields are superimposed to allow stereoscopic vision, which improves motor skills. The ipsilateral projection of the temporal half of the retina is necessary to fuse both images of the retina homotopically in the brain (Fig. 2). If the complete crossing occurred as in the lower vertebrates, the information would be compromised. ${ }^{3}$ In humans, this occurs in albinism and related disorders. ${ }^{42}$

In addition, Cajal explained how the crossing of the tactile pathways is necessary to allow visual and tactile inputs to integrate in the brain, generating a global sensory representation contralateral to the stimulus. In turn, the motor pathway follows the crossed sensory representation to allow the correct limb to be activated with sensory stimulation (Fig. 3). According to Cajal, there is an inverse relationship between the number of nerve fibers that cross in the chiasm and the proportion of crossed corticospinal tract fibers. ${ }^{30,42}$ 


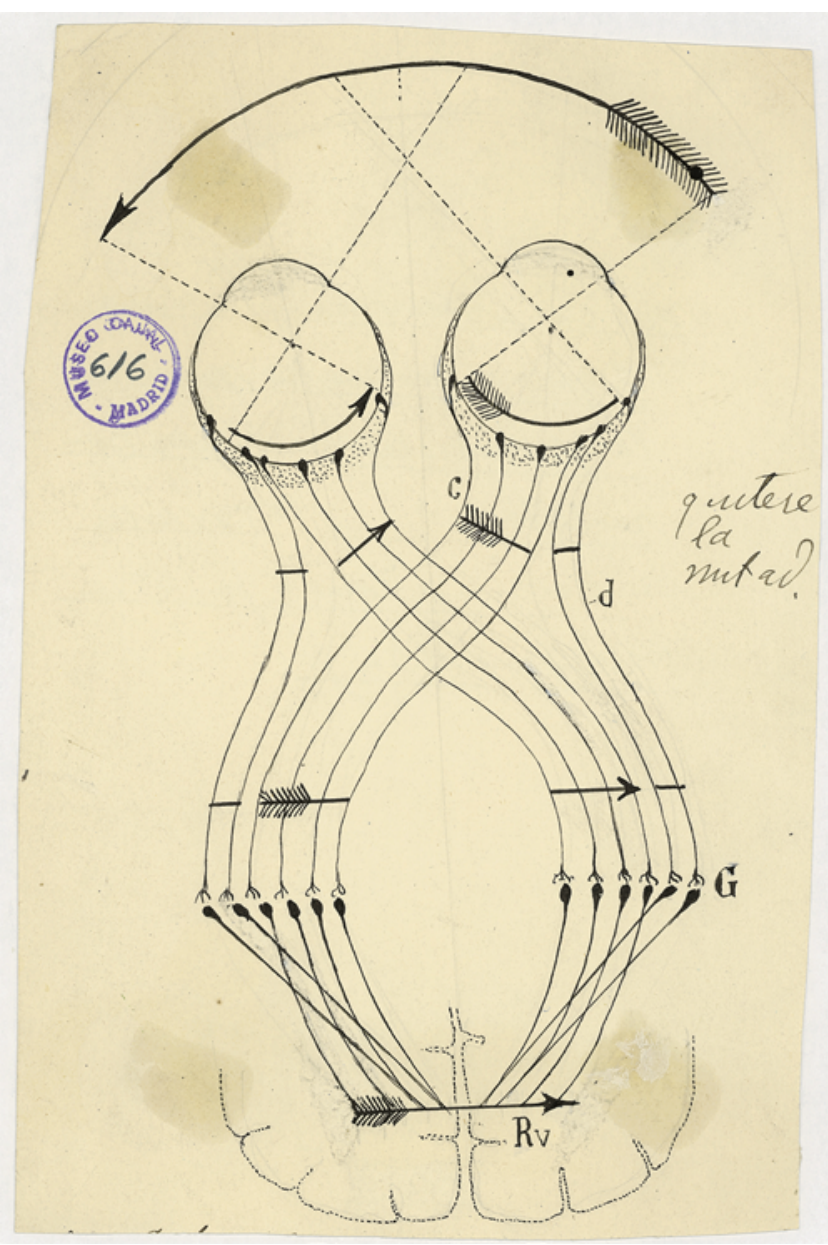

FIG. 2. Ramón y Cajal's schematic drawing showing an optic pathway with a nerve fiber decussation in the chiasm allowing an accurate cortical representation of the object. Reproduced from Ramón y Cajal S:

Estructura del kiasma óptico y teoría general de los entrecruzamientos de las vías nerviosas. Rev Trim Micrografica 3:15-66, 1898. Public domain. Courtesy of the Cajal Institute, "Cajal Legacy," Spanish National Research Council (CSIC), Madrid, Spain.

When first described, Cajal's theory spread widely in the scientific community and it was quickly translated into other languages, such as German and English. ${ }^{31}$ In the German version published along with Johannes Bressler (1866-1942), Paul Flechsig (1847-1929), the renowned neuroanatomist from Leipzig, highlights Cajal's capacity for abstraction in developing a functional and teleological theory based on his anatomical findings, ${ }^{5}$ and influenced several scientists (Kölliker, Havet, and Marquez among them) to pursue this area of research. ${ }^{31}$

Interestingly, after Cajal, other authors also associated the midline crossing of the sensorimotor pathways with the anatomy of the optic chiasm. Francis Dixon, an English physician, published a theory similar to Cajal's in 1907. According to the author, this theory was suggested by Prof. G. D. Thane in a conversation; ${ }^{14}$ a decade later, after new insights on the cortical representation of the visual input, Dixon added a "vertical" correlation between the visual and sensorimotor pathways. ${ }^{13,33}$

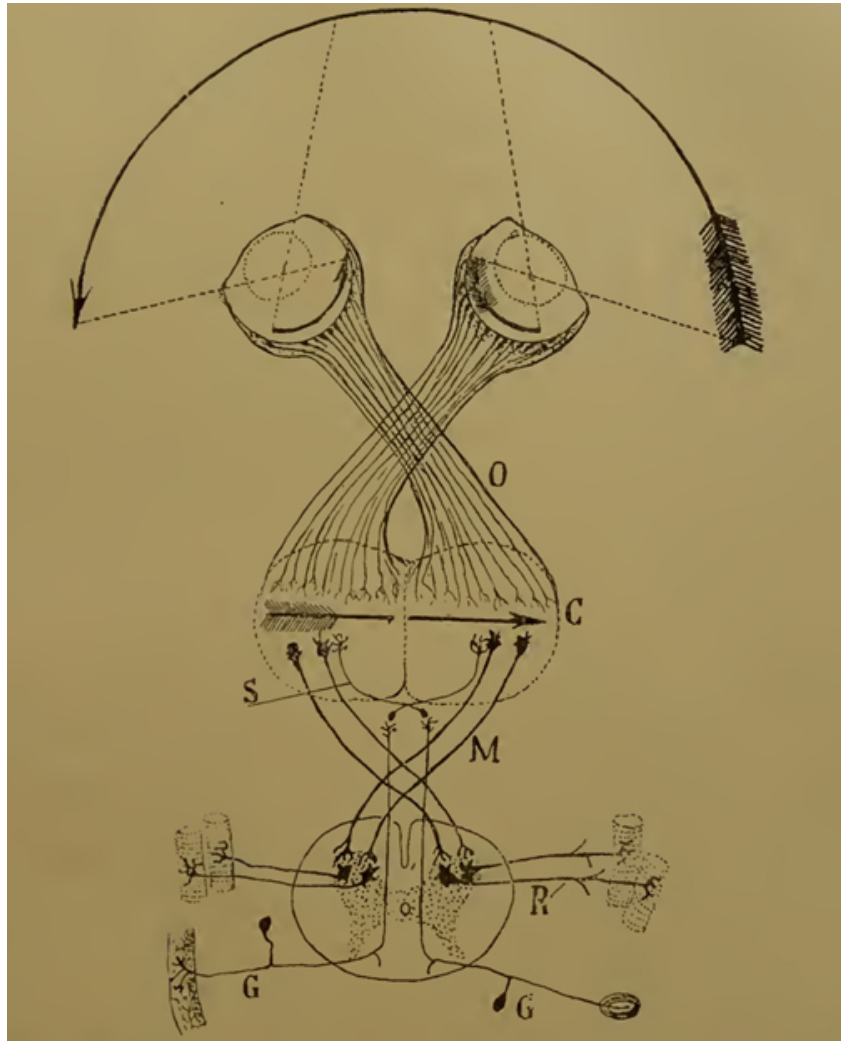

FIG. 3. Ramón y Cajal's schematic drawing showing the midline crossing of sensorimotor pathways to compensate optic decussation and, consequently, achieve cortical integration of the three systems. Reproduced from Ramón y Cajal S, Bresler J: Die Struktur des Chiasma Opticum: nebst einer allgemeinen Theorie der Kreuzung der Nervenbahnen. Leipzig: Johann Abrosius Barth, 1899. Public domain. Accessed from https://archive.org/details/b22384753/page/n2; courtesy of The Royal College of Surgeons of England.

Among the scientists who were influenced by Cajal was another pioneer of his time, Wilder Graves Penfield (1891-1976). Cajal's nerve fiber crossing theory and the global sensory and motor integration in the same cerebral hemisphere laid the scientific bases for Penfield's later topographic studies. In fact, Penfield spent 6 months in Spain working in the laboratory of Cajal's pupil, Pio Del Rio Hortega. ${ }^{43}$ During his stay in Spain, Penfield learned and made even more modifications to staining techniques originally used by Cajal and advanced his studies on brain injuries, beginning with his deductions on the possible role of glial cells in epilepsy. ${ }^{16}$ We can see the connection between both scientists in the book edited by Penfield in 1932, dedicated to Cajal, i.e., Cytology and Cellular Pathology of the Nervous System. ${ }^{9}$ This book on neuropathology remains a basic foundation for modern books on the subject.

Twenty-five years after the initial description of his theory, Rámon y Cajal revisited the topic in his memoirs and concluded that his theory of the compensatory decussation of the motor and sensory track, although probable, should be the subject of a more comprehensive research effort. ${ }^{31}$ Notwithstanding this caveat, since its publication Cajal's theory has played a central role in the understand- 
ing of the nerve-tract midline crossing and for almost a century has been the most plausible explanation of contralateral forebrain organization, a cornerstone of modern functional neuroanatomy. Although in the recent decades several alternative theories have been developed based on structural phylogenetic processes (summarized below), Cajal's theory remains one of the most accepted hypotheses among the scientific community.

\section{Rámon y Cajal's Theory and Modern Alternative Theories on Nerve Track Midline Crossing}

To date, an adaptive benefit of fiber decussation has not been established. Different alternative theories have been proposed to explain the advantages of this fiber crossing. These explanations range from simple mechanical interpretations to elaborate theological arguments about CNS image processing. At the simplest level, it has been argued that the abundance of crossing fiber bundles makes the brain mechanically more stable due to a cord effect. Another very simplistic argument states that the crossed pathways are the evolution from a primitive spherical brain to a bilateral and symmetrical brain. They argue that as fiber bundles are longer and, therefore, more important, they will cross the midline. This argument is not valid for vertebrates and invertebrates, because although invertebrates may present with decussation of their nerve fibers, it is not the general rule. ${ }^{2}$

In 1965, Braitenberg refuted Cajal's theory by arguing that the decussation of the nerve fibers in the chiasm, although sufficient, is not essential to correct the discontinuity of the image obtained in the visual cortex. Consequently, according to the author, the optical inversion could have been corrected without the decussation in the chiasm. On the contrary, however, based on the assumption that a vertebrate ancestor was governed primarily by an olfactory stimulus, the decussation would have occurred because cross-sensorimotor connections would have certain advantages in terms of taxis-kinesis behavior. ${ }^{2}$

Conversely, more than 4 decades ago, Sarnat and Netsky argued that the crossing of the motor pathways is a response to the defensive coiling reflex as observed in the amphioxus, an animal behavior of withdrawing from the threatening side. In response to a unilateral threat, this reflex would elicit the activation of the contralateral locomotor system, hence requiring the midline crossing of the motor pathway. ${ }^{36}$ However, coiling reflexes in vertebrates can be found in invertebrates, which do not present with nerve tract decussations. ${ }^{21}$

A more elaborate theory is the one proposed by Serge Vulliemoz et al. in 2005. They argue that in primitive species a threatening stimulus on the left side of the body will be perceived by the right cerebral hemisphere and this will evoke a contraction of the right-half muscles, through the noncrossed pathways (vestibulospinal and reticulospinal). This contraction of the right half of the body will move the organism away from the menacing stimulus. A vertebrate with extremities, in contrast, would try to escape from a left-side stimulus by extending the left extremities. In this case, the less primitive motor pathways (the crossed corti- cospinal and rubrospinal pathways) will be responsible for the response. ${ }^{42}$

By using a topological approach, it has also been proposed that fiber midline crossing is an essential anatomical substrate for complex 3D somatotopic function and that the spatially dependent and phylogenetically advanced functions tend to rely on decussated pathways. ${ }^{39}$ More recently, Loosemore proposed that the contralateral organization of the vertebrate's forebrain resulted from the inversion of visual images in an ancestral vertebrate with a single frontal eye. According to this author, the contralaterality developed as the concavity of the single retina increased. Loosemore explained how this phenomenon arose early in single-eyed vertebrates and how the progression to the formation of the optic chiasm occurred later. ${ }^{23}$

Perhaps the current, more accepted explanations for the midline crossing are the recently described "twist theories," i.e., the somatic twist theory by Kinsbourne ${ }^{21}$ and the axial twist in two steps by de Lussanet and Osse. ${ }^{10,11}$ According to them, the decussation could be a structural characteristic that arose in the course of an unrelated phylogenetic adaptation: a ventral-dorsal turn and the persistence of decussation in chordates and vertebrate species would be attributed to the adaptive advantage of the architectural change in the body plan. According to de Lussanet and Osse, Cajal's theory has major limitations. Probably their more significant criticism is that Cajal's statement-that in the mammalian visual cortex, the crossing in the optic chiasm allows continuity of the image-is erroneous. ${ }^{10,11}$ Victor et al. has also tried to discredit Cajal's theory by reporting a case of a patient with exclusively ipsilateral optical projections that preserves the continuity of his visual field, contrary to Cajal's theory. ${ }^{41}$

As noted previously, to date no theory has managed to completely refute Cajal's postulates. Many of the people who disagree with his theory argue that they do not see an advantage of fiber crossing. But as Cajal himself mentions in his memoirs, he does not assert that such a crossing has a purpose, but having originated from physical-chemical causes, the crossing of the fibers has prevailed and has been perpetuated by being advantageous. ${ }^{31}$

\section{Clinical Implications and Molecular Mechanisms Involved in Nerve Crossing}

Different congenital diseases have been related to $a b-$ normal or null decussation of the pyramidal pathway. Clinically, the motorway abnormality can be presented as mirror movements, which are unintended movements that occur in a hemibody mimicking the voluntary ones of the contralateral limbs and it usually involves the hand. Among the diseases presenting with mirror movements, the most common ones are the Klippel-Feil and X-linked Kallmann's syndromes. Anomalies of fiber decussation may also result in horizontal gaze palsy and progressive scoliosis. The abnormalities in the crossing of the nerve pathways can be diagnosed with noninvasive techniques such as transcranial magnetic stimulation and diffusion tensor imaging. ${ }^{42}$

These syndromes have helped us reach a better understanding of the molecular mechanisms responsible for fi- 
ber decussation..$^{37}$ Recently, $\mathrm{ROBO} 3$ has been implicated in diseases such as progressive scoliosis and horizontal gaze palsy, ${ }^{42}$ and it has been described that the divergent Robo family protein Robo3 is a negative regulator of slit responsiveness, required for midline crossing by commissural axons. Consequently, the elimination of $\mathrm{ROBO} 3$ in mice prevents crossing of the commissural pathways. ${ }^{35} \mathrm{~Pa}-$ tients with homozygous mutations in $\mathrm{ROBO}$, as in horizontal palsy gaze, present with long-pathway decussation alterations.

In Joubert's syndrome, mental retardation is also present, most likely due to the difficulties of task processing associated with a crossed medial lemniscus along with an uncrossed motor pathway. ${ }^{37}$ Recently, a gene implicated in Joubert's syndrome, AHIl, has also been identified. ${ }^{42}$

Netrins are also involved in the decussation of axons. These molecules attract axons to the midline, and mice lacking these molecules have alterations in the contralateral projection nerve pathways. ${ }^{17,38}$ At the same time, we have neuronal adhesion molecule L1, whose alteration in mice causes atrophy of the corticospinal tract and its incomplete decussation. ${ }^{7}$ In humans, this gene mutation has been described in several diseases such as X-linked hydrocephalus, CRASH (corpus-callosum agenesis, adducted thumbs, spasticity, and hydrocephalus), and MASS (mental retardation, aphasia, shuffling gate, and adducted thumbs). ${ }^{15}$ Regardless of what happens with this gene in rodents, these diseases do not have impairment of the pyramidal pathway. ${ }^{7,12,15}$

As mentioned above, patients with X-linked Kallman's syndrome may also present with an anomalous corticospinal pathway or mirror movements. This happens because the surface protein Anosmin-1, encoded by the Kall gene, which is the gene responsible for this syndrome, shares similarities with L1. Anosmin-1, as its name indicates, is involved in the atrophy of the olfactory bulb of this syndrome. In turn, given that the olfactory and pyramidal tracts are formed at the same time in embryonic life, this syndrome may involve the impairments in the pyramidal tract previously explained. ${ }^{20,40}$ Additionally, ephrins are repulsive molecules present along the midline of the CNS, which are not present in the bulb, allowing the decussation of the pyramids. Abnormalities in these molecules have been associated with mirror movements in animals. ${ }^{42}$

\section{Future Perspectives Injury and Plasticity}

One unresolved question is the role of decussated pathways when an injury to a cerebral hemisphere occurs. After a brain infarction, not all contralateral muscles are affected equally and ipsilateral paresis may occur. While the dysfunction of distal muscles of the hands reflects injury in lateral corticospinal tracts, it is believed that paresis of the ipsilateral shoulder is due to damage of ventral corticospinal tracts, which mainly control proximal muscles. ${ }^{8}$ As explained by Cajal, muscles receiving bilateral innervation, such as those of the upper part of the face or involved in chewing, are normally spared thanks to the preservation of the contralateral innervation. ${ }^{6,8}$ Therefore, we might think that the contralateral cortex plays an important role when recovering after hemispheric damage, perhaps due to the ipsilateral corticospinal projections. ${ }^{42}$ We can explore the ipsilateral motor-evoked potentials through transcranial magnetic stimulation. These ipsilateral potentials are absent in most healthy subjects, while they can be observed in some patients after a cerebral infarction (e.g., stimulation of the right hemisphere in a patient with a left cerebral infarction leads to movement of the right limb). Even so, these ipsilateral responses have been associated with a worse prognosis, because they probably represent the unmasking of the intact hemisphere and not an attempt to compensate for the deficit. ${ }^{42}$ The knowledge of the purpose of nerve decussation, together with the molecular mechanisms involved in the regulation of this fiber crossing, may help us to dispel this doubt in the future.

\section{Brain Dominance}

Recent investigations focusing on deciphering the advantages of brain lateralization and experiments showing the lateralization of invertebrates led to the hypothesis that this characteristic gives a favorable selective advantage. , 19,27 Recently it has been documented that cerebral lateralization increases neuronal capacity because it allows parallel and separate processing of the two hemispheres in animals such as chicks, marmosets, or pigeons. ${ }^{34}$ It appears that this right-left differentiation increases neuronal capacity in different species, independent of the variation in interspecies neuronal capacity. ${ }^{4}$ Even so, the cause of such asymmetry remains a mystery.

\section{Conclusions}

Cajal's hypothesis remains one of the most supported theories to date. None of the current hypotheses have gained general recognition. The decussation of nerve pathways depends on many more genes than those we know today. In the future, as our understanding of midline-crossing molecular pathways increases, we might improve our teleological notions on the evolutionary mystery of nerve-tract midline crossing.

\section{Acknowledgments}

We thank Dr. Ricardo Martínez Murillo and the Cajal Institute, “Cajal Legacy,” Spanish National Research Council (CSIC), Madrid, Spain, for helping with the copyrighted images.

\section{References}

1. Aminoff MJ: The life and legacy of Brown-Séquard. Brain 140:1525-1532, 2017

2. Braitenberg V: Taxis, kinesis and decussation. Prog Brain Res 17:210-222, 1965

3. Breitenfeld T, Jurasic MJ, Breitenfeld D: Hippocrates: the forefather of neurology. Neurol Sci 35:1349-1352, 2014

4. Byrne RA, Kuba MJ, Meisel DV: Lateralized eye use in Octopus vulgaris shows antisymmetrical distribution. Anim Behav 68:1107-1114, 2004

5. Cajal SR y, Bresler J: Die Struktur des Chiasma opticum: nebst einer allgemeinen Theorie der Kreuzung der Nervenbahnen. Leipzig: Johann Ambrosius Barth, 1899

6. Carr LJ, Harrison LM, Stephens JA: Evidence for bilateral innervation of certain homologous motoneurone pools in man. J Physiol 475:217-227, 1994 
7. Cohen NR, Taylor JSH, Scott LB, Guillery RW, Soriano P, Furley AJW: Errors in corticospinal axon guidance in mice lacking the neural cell adhesion molecule L1. Curr Biol 8:26-33, 1998

8. Colebatch JG, Gandevia SC: The distribution of muscular weakness in upper motor neuron lesions affecting the arm. Brain 112:749-763, 1989

9. Cytology and cellular pathology of the nervous system. Arch Intern Med (Chic) 50:508-509, 1932

10. de Lussanet MHE, Osse JWM: An ancestral axial twist explains the contralateral forebrain and the optic chiasm in vertebrates. Anim Biol Leiden Neth 62:193-216, 2012

11. de Lussanet MHE, Osse JWM: Decussation as an axial twist: a comment on Kinsbourne (2013). Neuropsychology 29:713714, 2015

12. Demyanenko GP, Tsai AY, Maness PF: Abnormalities in neuronal process extension, hippocampal development, and the ventricular system of L1 knockout mice. J Neurosci 19:4907-4920, 1999

13. Dixon AF: Why are the cerebral motor and sensory cortical areas arranged in an inverted order? Dublin J Med Sci 145:154-160, 1918

14. Dixon AF: Why are the great motor and sensory tracts of the central nervous system crossed? Dublin J Med Sci 124:1-4, 1907

15. Dobson CB, Villagra F, Clowry GJ, Smith M, Kenwrick S, Donnai D, et al: Abnormal corticospinal function but normal axonal guidance in human L1CAM mutations. Brain 124:2393-2406, 2001

16. Feindel W: Wilder Penfield: his legacy to neurology. To praise an absent friend. Can Med Assoc J 116:1365-1367, 1977

17. Finger JH, Bronson RT, Harris B, Johnson K, Przyborski SA, Ackerman SL: The netrin 1 receptors Unc5h3 and Dcc are necessary at multiple choice points for the guidance of corticospinal tract axons. J Neurosci 22:10346-10356, 2002

18. Finger S: Minds Behind the Brain: A History of the Pioneers and Their Discoveries. New York: Oxford University Press, 2005

19. Hobert O, Johnston RJ Jr, Chang S: Left-right asymmetry in the nervous system: the Caenorhabditis elegans model. Nat Rev Neurosci 3:629-640, 2002

20. Hu Y, Tanriverdi F, MacColl GS, Bouloux PMG: Kallmann's syndrome: molecular pathogenesis. Int J Biochem Cell Biol 35:1157-1162, 2003

21. Kinsbourne M: Somatic twist: a model for the evolution of decussation. Neuropsychology 27:511-515, 2013

22. Kölliker A: Handbuch der Gewebelehre des Menschen. Nervensystem des Menschen und der Thiere Bd. 2. Leipzig: Engelmann, 1896

23. Loosemore RG: The inversion hypothesis: A novel explanation for the contralaterality of the human brain. Biosci Hypotheses 2:375-382, 2009

24. Luco JV: Santiago Ramón y Cajal. ARS MEDICA Rev Ciencias Médicas 15:77-80, 1985 (https://arsmedica.cl/ index.php/MED/article/view/809/705) [Accessed July 15, 2019]

25. Michel J: Lehrbuch der Augenheilkunde. Wiesbaden, Germany: Bergmann, 1890

26. Naderi S, Türe U, Pait TG: History of the spinal cord localization. Neurosurg Focus 16(1):E15, 2004

27. Pascual A, Huang KL, Neveu J, Préat T: Neuroanatomy: brain asymmetry and long-term memory. Nature 427:605606, 2004

28. Pearce JM: Johann Jakob Wepfer (1620-95) and cerebral haemorrhage. J Neurol Neurosurg Psychiatry 62:387, 1997

29. Pearce JMS: The neurology of aretaeus: radix pedis neurologia. Eur Neurol 70:106-112, 2013
30. Ramón y Cajal S: Estructura del kiasma óptico y teoría general de los entrecruzamientos de las vías nerviosas, in Revista Trimestral Micrográfica. Madrid: Nicolas Moya, 1898, Vol 3, pp 15-66

31. Ramón y Cajal S: Recuerdos de Mi Vida: Historia de Mi Labor Científica. Madrid: Alianza, 1981

32. Rasmussen AT, Peyton WT: The course and termination of the medial lemniscus in man. J Comp Neurol 88:411-424, 1948

33. Rogalski T: The visual paths in a case of unilateral anophthalmia with special reference to the problem of crossed and uncrossed visual fibres. J Anat 80:153-159, 1946

34. Rogers LJ, Zucca P, Vallortigara G: Advantages of having a lateralized brain. Proc Biol Sci 271 (Suppl 6):S420-S422, 2004

35. Sabatier C, Plump AS, Le Ma, Brose K, Tamada A, Murakami F, et al: The divergent Robo family protein rig-1/Robo3 is a negative regulator of slit responsiveness required for midline crossing by commissural axons. Cell 117:157-169, 2004

36. Sarnat HB, Netsky MG: Evolution of the Nervous System. New York: Oxford University Press, 1974

37. Schutta HS, Abu-Amero KK, Bosley TM: Exceptions to the Valsalva doctrine. Neurology 74:329-335, 2010

38. Serafini T, Colamarino SA, Leonardo ED, Wang H, Beddington R, Skarnes WC, et al: Netrin-1 is required for commissural axon guidance in the developing vertebrate nervous system. Cell 87:1001-1014, 1996

39. Shinbrot T, Young W: Why decussate? Topological constraints on 3D wiring. Anat Rec (Hoboken) 291:1278-1292, 2008

40. Soussi-Yanicostas N, de Castro F, Julliard AK, Perfettini I, Chédotal A, Petit C: Anosmin-1, defective in the X-linked form of Kallmann syndrome, promotes axonal branch formation from olfactory bulb output neurons. Cell 109:217-228, 2002

41. Victor JD, Apkarian P, Hirsch J, Conte MM, Packard M, Relkin NR, et al: Visual function and brain organization in non-decussating retinal-fugal fibre syndrome. Cereb Cortex 10:2-22, 2000

42. Vulliemoz S, Raineteau O, Jabaudon D: Reaching beyond the midline: why are human brains cross wired? Lancet Neurol 4:87-99, 2005

43. Zamora-Berridi GJ, Pendleton C, Ruiz G, Cohen-Gadol AA, Quiñones-Hinojosa A: Santiago Ramón y Cajal and Harvey Cushing: two forefathers of neuroscience and neurosurgery. World Neurosurg 76:466-476, 2011

\section{Disclosures}

The authors report no conflict of interest concerning the materials or methods used in this study or the findings specified in this paper.

\section{Author Contributions}

Conception and design: all authors. Acquisition of data: Mora, Velásquez. Analysis and interpretation of data: Mora, Velásquez. Drafting the article: Mora. Critically revising the article: Mora, Velásquez. Reviewed submitted version of manuscript: Mora, Velásquez. Approved the final version of the manuscript on behalf of all authors: Martino. Study supervision: Martino, Velásquez.

\section{Correspondence}

Juan Martino: Hospital Universitario Marqués de Valdecilla and Fundación Instituto de Investigación Valdecilla, Santander, Spain. juan.martino@hotmail.com. 